\title{
Experimental Research on Cavitation Evolution and Movement Characteristics of the Projectile during Vertical Launching
}

\author{
Siru Chen, Yao Shi * ${ }^{\mathbb{D}}$, Guang Pan and Shan Gao
}

check for updates

Citation: Chen, S.; Shi, Y.; Pan, G.; Gao, S. Experimental Research on Cavitation Evolution and Movement Characteristics of the Projectile during Vertical Launching. J. Mar. Sci. Eng. 2021, 9, 1359. https://doi.org/ 10.3390/jmse9121359

Academic Editor: Fabio Bruno

Received: 4 October 2021

Accepted: 23 November 2021

Published: 1 December 2021

Publisher's Note: MDPI stays neutral with regard to jurisdictional claims in published maps and institutional affiliations.

Copyright: (c) 2021 by the authors. Licensee MDPI, Basel, Switzerland. This article is an open access article distributed under the terms and conditions of the Creative Commons Attribution (CC BY) license (https:// creativecommons.org/licenses/by/ $4.0 /)$.
Key Laboratory of Unmanned Underwater Projectile, School of Marine Science and Technology, Northwestern Polytechnical University, Xi'an 710072, China; chen99@mail.nwpu.edu.cn (S.C.); panguang@nwpu.edu.cn (G.P.); gaoshan111@mail.nwpu.edu.cn (S.G.)

* Correspondence: shiyao@nwpu.edu.cn

\begin{abstract}
Aiming at the problem of unsteady cavitation during a projectile's vertical water-exit process, scaled model experiments were carried out based on the self-designed underwater launch platform and high-speed cameras, which focus on changes in cavitation shape and projectile posture. In this paper, the general process of the cavitation evolution and projectile's movement is described; the relationship between the re-entry jet, local cavitation number and cavitation stability is discussed. Meanwhile, the effect of head forms and launch speeds on the cavitation evolution and movement characteristics is analyzed, including $60^{\circ}$ cone, $90^{\circ}$ cone and hemispherical head with velocity of $16.8 \mathrm{~m} / \mathrm{s}, 18.5 \mathrm{~m} / \mathrm{s}$ and $20.0 \mathrm{~m} / \mathrm{s}$, whose launch cavitation number is $0.714,0.589$ and 0.504 . The results show that the attached cavities fall off from the bottom up under the influence of the end-reentry jet and the shedding frequency declines when the launch cavitation number decreases. The cavitation growth of $60^{\circ}$ cone is easily disturbed by the air mass near the launcher, the cavitation development of $90^{\circ}$ cone is characterized by small-scale and high-frequency growth and shedding, while the hemispherical head is not prone to cavitation. Moreover, increasing the speed can improve the stability of cavitation development and the projectile's movement.
\end{abstract}

Keywords: projectile; unsteady cavity; head form; launch speed; water-exit experiment

\section{Introduction}

With the increasingly severe maritime security situation, all countries are actively strengthening their maritime defense forces to defend their sovereignty, independence and territorial integrity. As an important part of naval equipment, submarine projectiles have the advantages of good concealment and high lethality, whose underwater launch technology is one of the key technologies to enhance our country's future combat capabilities. At present, only a few countries in the world have relatively mature underwater launch technology of submarine projectiles.

Unsteady cavitation research has been the difficulty of underwater vertical launch, as the complex flow field involving multiphase coupling makes it hard to analyze the dynamic characteristics of projectiles. The evolution process of the cavitation from growth, shedding to collapse affects the motion stability of projectiles, and even damages the surface and performance of projectiles [1]. Therefore, further study on the mechanism and influence of the unsteady cavitation will have great significance to the optimization of the projectile's design and the development of underwater launch technology.

The early cavitation flow theory [2,3] has many limitations, which makes it difficult to solve unsteady cavitation problems, while the cavitation collapse theory [4,5] is limited to the single bubble model as well. The current research mainly relies on simulations and experiments, especially in hydrofoil cavitation, which is relatively mature. By modifying the simulation model [6] and improving the experimental observation technology, combined with mechanical analysis [7], great achievements have been made in cavitation mechanism, morphological definition and stability investigation. Kubota et al. [8] and Le et al. [9] 
experimentally analyzed the unsteady cavitation evolution of the hydrofoil and pointed out that the cavitation stability is related to the influence of the jet and vortex. Kjeldsen et al. [10] and Wang et al. [11] made experimental observations and three-dimensional simulations on the cavitation characteristics of NACA0015 hydrofoils with LDV (Laser Doppler Velocimetry) and LES (Large Eddy Simulation), studied the influence of the angle of attack and cavitation number on sheet and cloud cavitation. Huang et al. [12] analyzed the periodic cavitation evolution of Clark-Y hydrofoil based on the water tunnel test with PIV (Particle Image Velocimetry), and discussed the relationship between cavitation instability and vorticity. The research conclusions on hydrofoil cavitation provides a theoretical basis for the discussion on projectile's unsteady cavitation characteristics.

The cavitation circumfluence of horizontally launched projectiles is similar to that of hydrofoils, but the noise characteristics are still different [13]. While investigating the cavitation stability, the related literatures also summarize the influence of head shape, cavitation number, speed and angle of attack on cavitation and dynamic characteristics. Yu et al. [14] studied the correlation between cavitation shedding and re-entry jet through SHPB (Split-Hopkinson pressure bar) test and LES simulation. Wei et al. [15] and Hu et al. [16] discussed the evolution differences of the cavitation shape and vortex structure under various head shapes with PIV and dynamic force measurement. Chen et al. [17] and Wan et al. [18] analyzed the change of cavitation collapse pressure during the deceleration process and the inhibitory of increasing the angle of attack on the sheet cavitation shedding simulatively. Zhao et al. [19] observed the cavitation development and projectile's movement at different speeds with high-speed cameras. Sun et al. [20] described the bubble evolution under different cavitation numbers and obtained the time-frequency characteristics of the pressure pulsation with closed-loop water tunnels and sampling systems.

There is gravity in the underwater vertical launch, involving complex cavitation collapse problems. The related results mostly rely on numerical simulation [21,22], while experimental research is rare. You et al. [23] simulated the cavitation collapse out of water and illustrated the effect of the impact pressure on the structure considering the fluidstructure interaction. Zhang et al. [24] and Liu et al. [25] analyzed the cavitation shape and pressure changes at different speeds and depths and their effects on the projectile's motion simulatively. Cao et al. [26] simulated the evolution of tail cavitation and discussed the causes of cavitation fluctuations and their interference with movement. Wang et al. [27,28] numerically and experimentally illustrated the relationship between cavitation shedding and re-entry jet, studied the mechanism of cavitation collapse and analyzed the effects of cross flow and deceleration on the cavitation characteristics. Chen et al. [29] simulated the cavitation development process and analyzed the influence of the angle of attack on the cavitation shedding and collapse with LES. Quan et al. [30] recorded the cavity shape and collapse pressure with high-speed cameras and pressure sensors, and found that the pressure pulse moves from the collapse point along the surface to the tail of projectiles, whose value is closely related to the bubble shape. Fu et al. [31] discussed the influence of launch speed and depth on bubble shape and projectile's posture through scaled model experiments. Song et al. [32] conducted water-exit tests on objects of various shapes and pointed out that velocity is the main parameter causing the deformation of the free liquid surface.

In summary, certain results have been achieved in the research on the cavitation stability of hydrofoils and projectiles. However, most of the tests were carried out in water tunnels, without considering the effect of gravity, which makes it difficult to discuss the problem of the water-exit cavitation collapse. Therefore, based on a self-designed underwater launch platform, this paper studies the cavitation evolution and projectile movement under different head forms and launch speeds during a scaled model vertical launch test to provide technical support for load analysis and structural design of submarine projectiles and provide theoretical references for the development of underwater launch technology in our country. The structure of this paper is as follows: Section 2 introduces the experimental 
platform and model in detail. Subsequently, Section 3 analyzes the causes of unsteady cavitation, investigates the effect of head forms with launch speeds on cavitation process through the experimental results and discusses the movement characteristics of underwater projectiles as well. Finally, the main conclusions are summarized in Section 4.

\section{Experimental Platform and Model}

The underwater launch platform consists of four parts: pneumatic launch system, control system, image acquisition system and protective recovery system, as shown in Figure 1. The test uses cold emission, in which the water tank size is $1.84 \mathrm{~m} \times 1.2 \mathrm{~m} \times 1.22 \mathrm{~m}$ and the water depth is about $0.8 \mathrm{~m}$. The pneumatic launch system is composed of an air compressor, a gas cylinder, a launch tube, an aluminum guide rail, etc. The air compressor provides gas to launch projectiles and changes supply gas flow to adjust the launch speed.

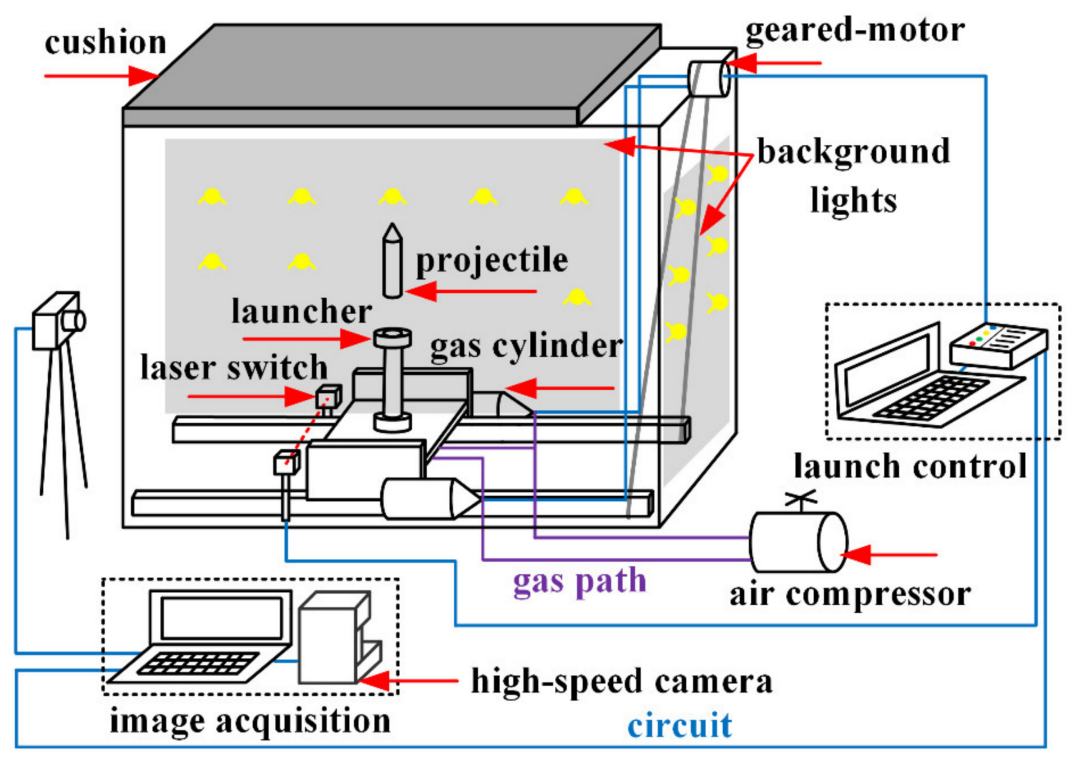

Figure 1. Major components of the underwater launching system.

The control system includes solenoid valves, laser switches, geared motors, and control circuits. During the test, two couples of laser switches are used as the trigger switch of control circuits and the anti-collision limit switch of the launch platform. The geared motor is started by control circuits to provide power for the launch platform and make its movement controllable along the guide, while the parameters are set on the control panel to achieve the ideal launch situation. The image acquisition system relies on SM-HS4M1K and Phantom high-speed cameras whose resolution is $640 \times 1024$ and sampling frequency is $1000 \mathrm{fps}$ and $3000 \mathrm{fps}$, respectively. Meanwhile, four news lights are used as the ambient light source. Before the test, it is necessary to adjust the focus, pixels, frame rate and position of cameras to obtain clear and centered photos. The protective recovery system includes cushions, lifting devices, recovery fixtures, etc. The cushion can reduce the impact of the collision load on the projectile and protect its head.

In order to study the influence of head forms on the cavitation shape and projectile motion, the test models in Figure 2 were designed with a diameter (D) of $20 \mathrm{~mm}$ and lengthto-diameter ratio (L/D) of 6 . The masses of the $60^{\circ}$ cone, $90^{\circ}$ cone and hemispherical head projectiles are $61.8 \mathrm{~g}, 63.1 \mathrm{~g}$ and $64.7 \mathrm{~g}$, respectively. The models are hollow and segmented, which can reduce the mass and be convenient to replace the head section. Besides this, sealing rings are installed at the head and tail with the middle section to prevent water ingress. 


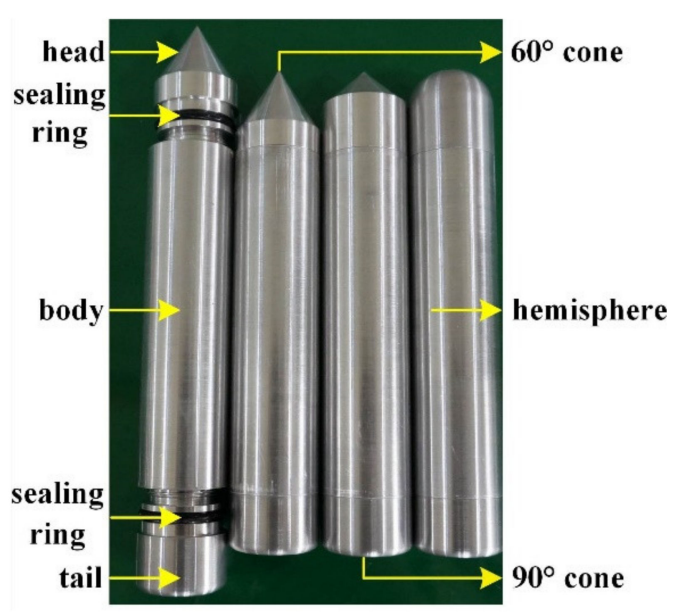

Figure 2. Experimental model design.

From the experiment, the definition of parameters and motion coordinates are shown in Figure 3. The water surface position and the time when the head touches the surface are specified as zero, and the value is negative underwater. The length and maximum thickness of bubbles are defined as as $l_{B}$ and $r_{B}$, whose dimensionless forms are defined as $L_{B}=l_{B} / D$ and $R_{B}=r_{B} / D$. The angle between the body axis and vertical direction is deflection angle $\theta$, and the clockwise is negative.

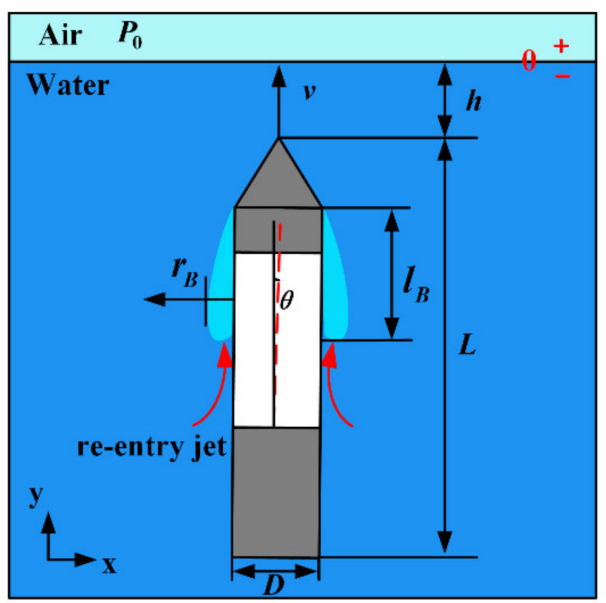

Figure 3. Schematic diagram of nomenclature.

Cavitation number is a dimensionless parameter that characterizes the cavitation state. However, in this paper, the local cavitation number [33] is introduced to describe the cavitation development at any time, whose definition is

$$
\sigma_{h}=\frac{P_{0}+\rho g h-P_{v}}{\frac{1}{2} \rho v^{2}}
$$

where $P_{0}$ is the ambient pressure, $P_{v}$ is the saturated vapor pressure at the local temperature, $\rho$ is the density of water, $v$ and $h$ are the speed and depth of the projectile at a certain time. When $v$ and $h$ are equal to the launch speed and depth at the corresponding time, the local cavitation number can be called the launch cavitation number.

\section{Results and Discussion}

In order to investigate the influence of the head forms and launch speeds on the evolution of bubble shape and the movement characteristics of the projectile, the experimental 
initial conditions involve three head forms of $60^{\circ}$ cone, $90^{\circ}$ cone and hemisphere as well as three launch speeds of $16.8 \mathrm{~m} / \mathrm{s}, 18.5 \mathrm{~m} / \mathrm{s}$ and $20.0 \mathrm{~m} / \mathrm{s}$, whose launch cavitation number is $0.714,0.589$ and 0.504 , respectively.

\subsection{The Effect of Head Forms on Cavitation Process}

This section analyzes the cavitation characteristics based on the water-exit tests of three head-shaped projectiles with a launch speed of $18.5 \mathrm{~m} / \mathrm{s}$. The unsteady cavitation evolution experiences three stages of growth, shedding and collapse in the process of the projectile launching, cruising and exiting water, as shown in Figures 4 and 5.

In the growth stage, the local pressure decreases at the shoulder of projectiles where the flow separation occurs, so that the water phase changes to form a transparent single bubble, into which the residual gas from the launcher escapes, and the length and thickness of cavities increase linearly with time to be stable.

In the shedding stage, the water flow moves back to the closure of bubbles, forming a reverse pressure gradient to generate a re-entry jet which advances along the projectile's surface and makes the cavitation cloud shed and rupture from bottom to top. With the generation of new bubbles at the shoulder, the size of cavities changes: when the bubbles merge or rupture, the length increases or decreases correspondingly while the thickness changes randomly, and the tail cavities pull off this time.

In the collapse stage, the bubbles collapse from bottom to top under the influence of environmental pressure changes and three phases of water, gas and water vapor when the projectile exits the water, forming a large splash.

Comparing cavitation differences in the size and morphology changes among three head forms, it can be found that the bubble cloud of $60^{\circ}$ cone head projectiles grows widely, which is easily interfered by the gas from the tube because of the large gap between the projectile and launcher. The cavitation size range of $90^{\circ}$ cone head projectiles is narrow, and its bubble cloud is early to occur and easy to shed and rupture frequently, making it so that the projectile deflection is obvious. The cavitation evolution and movement of hemispherical head projectiles is relatively stable, which is not easy to be affected by the free water surface.

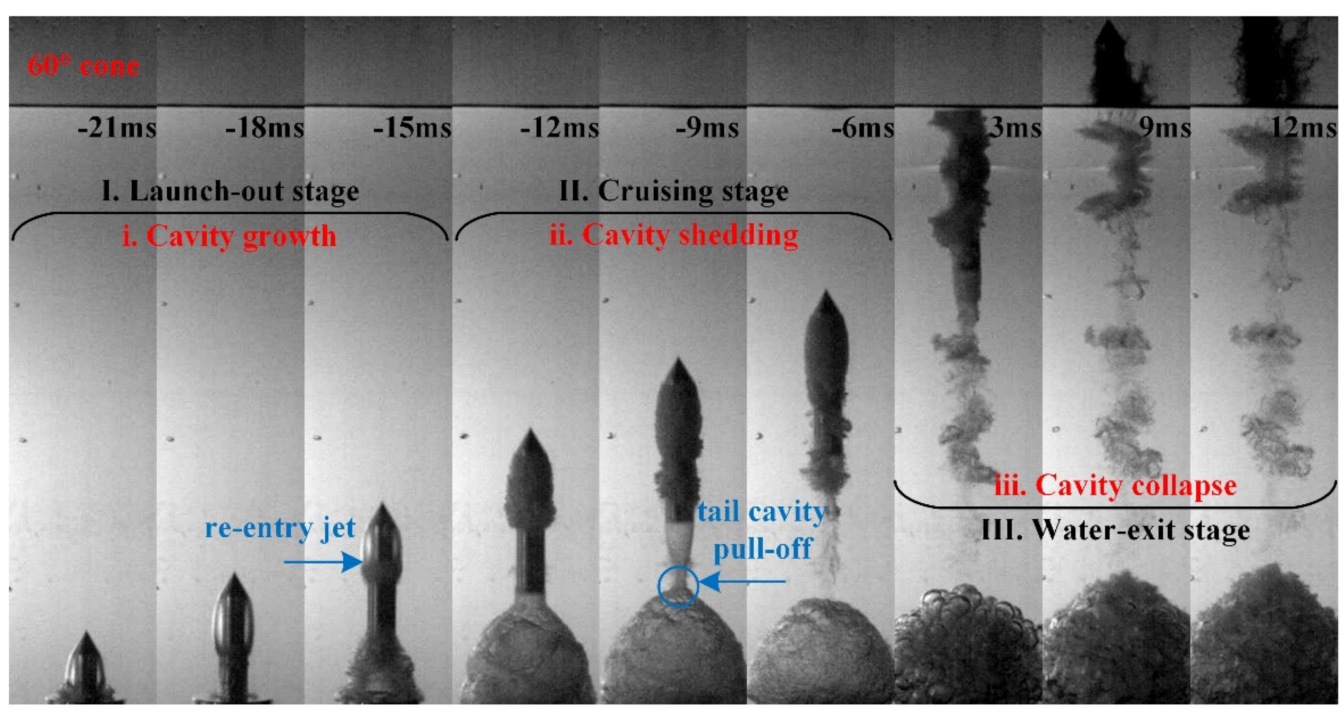

(a) $60^{\circ}$ cone head

Figure 4. Cont. 


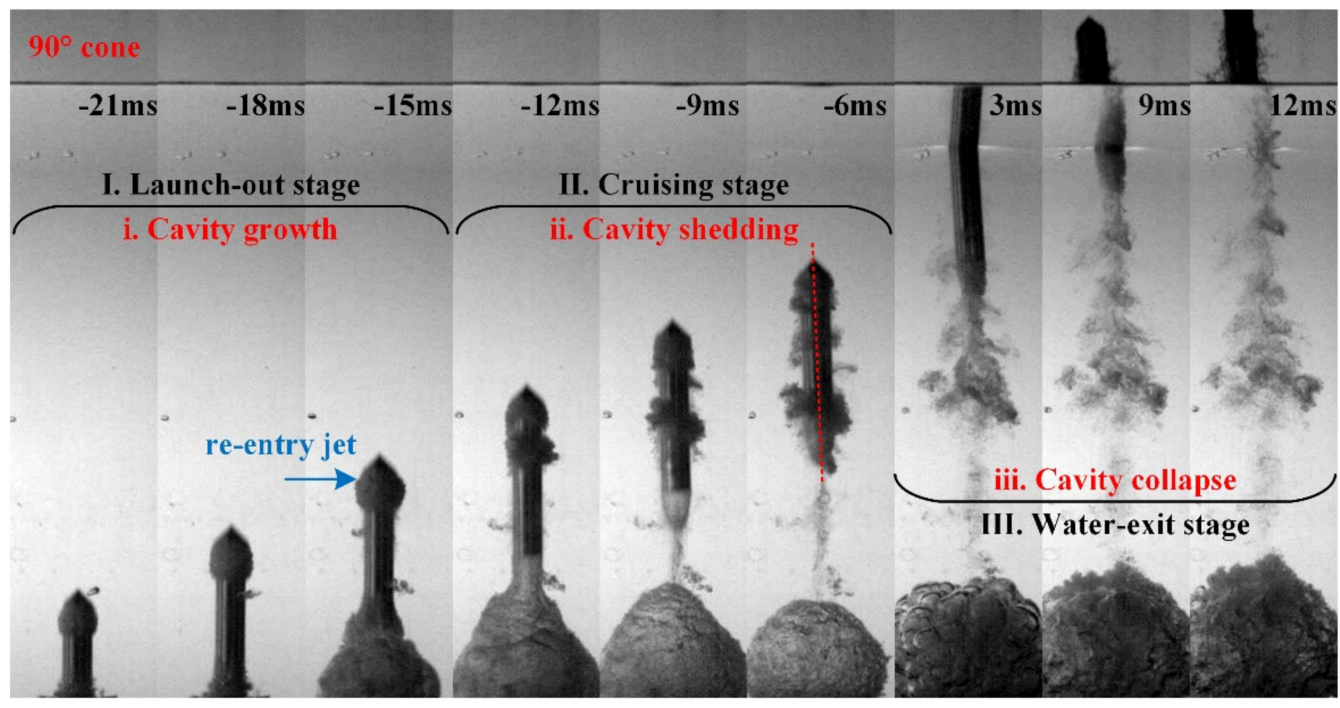

(b) $90^{\circ}$ cone head

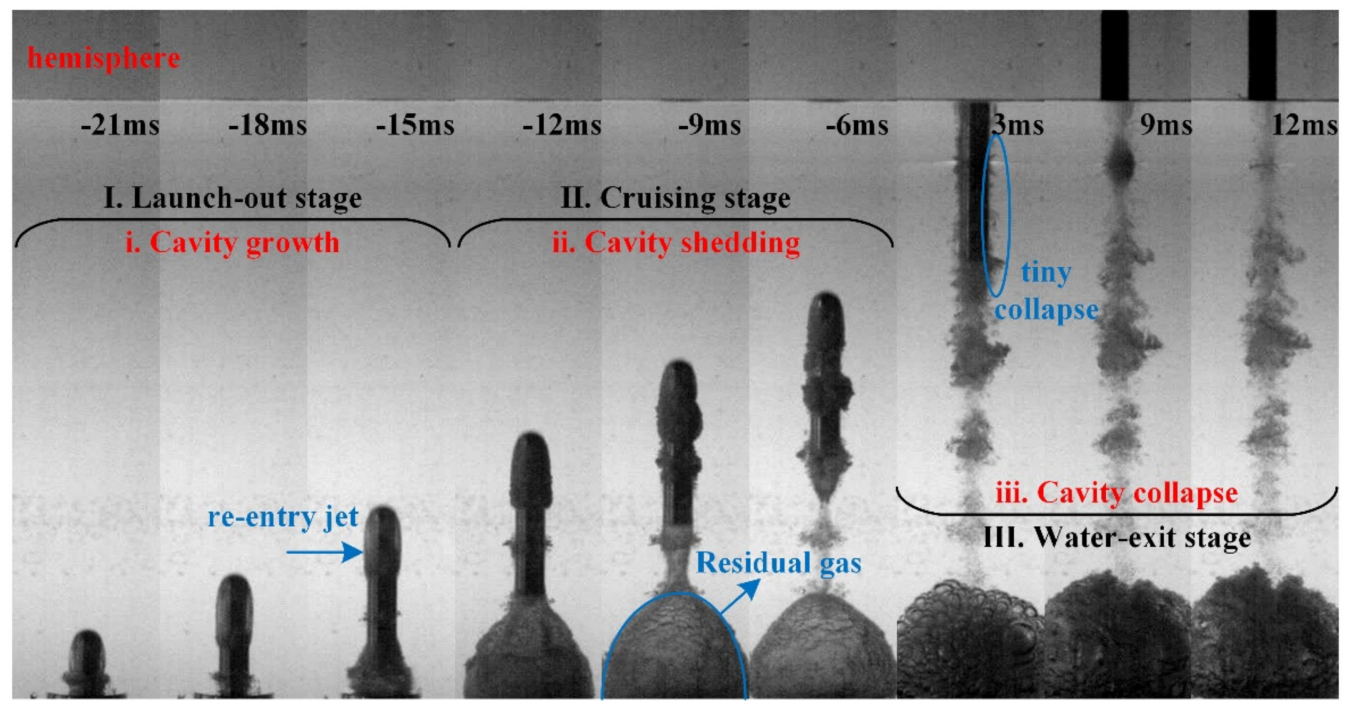

(c) hemispherical head

Figure 4. Unsteady cavitation evolution processes of three head-shaped projectiles. (a) $60^{\circ}$ cone head (b) $90^{\circ}$ cone head (c) hemispherical head. (I-III represent the projectile movement process, i-iii represent the cavitation evolution process).

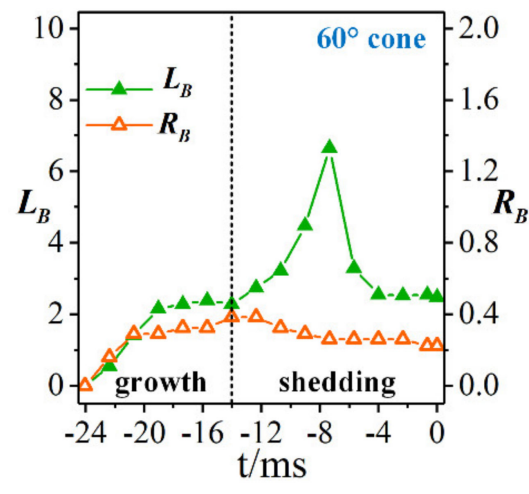

(a) $60^{\circ}$ cone head

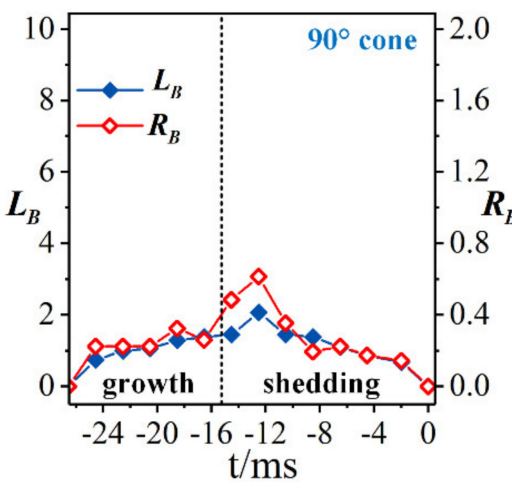

(b) $90^{\circ}$ cone head

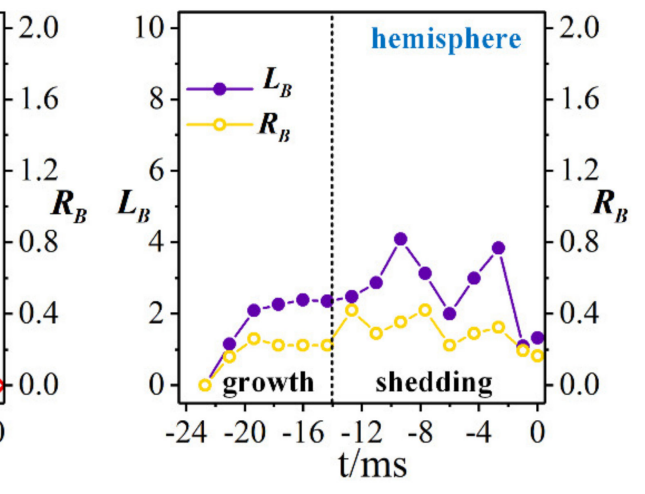

(c) hemispherical head

Figure 5. Variation curves of cavitation morphological parameters of three head-shaped projectiles. (a) $60^{\circ}$ cone head (b) $90^{\circ}$ cone head (c) hemispherical head. 
Since the re-entry jet affects the cavitation stability, its motion of three head forms in a period to study were selected, as shown in Figure 6, where the red arrow indicates its movement position. It can be seen from the figure that the re-entry jet is a mixture of water and gas, for its color is similar to the edge of bubbles, moving upstream from the closure of the cavity along the projectile's surface, so that the cavity shortens and sheds from bottom to top with its edge concave. The bubble of the $90^{\circ}$ cone head is short, while the fast-moving re-entry jet causes the cavity to grow and shed frequently in a small area, which intensifies the deflection of projectiles. This indicates that the increase in the generation length of the cavity and the motion time of the re-entry jet within one cycle can reduce the occurrence of the cavitation shedding in the whole process and alleviate the instability of the cavitation evolution and the projectile movement.

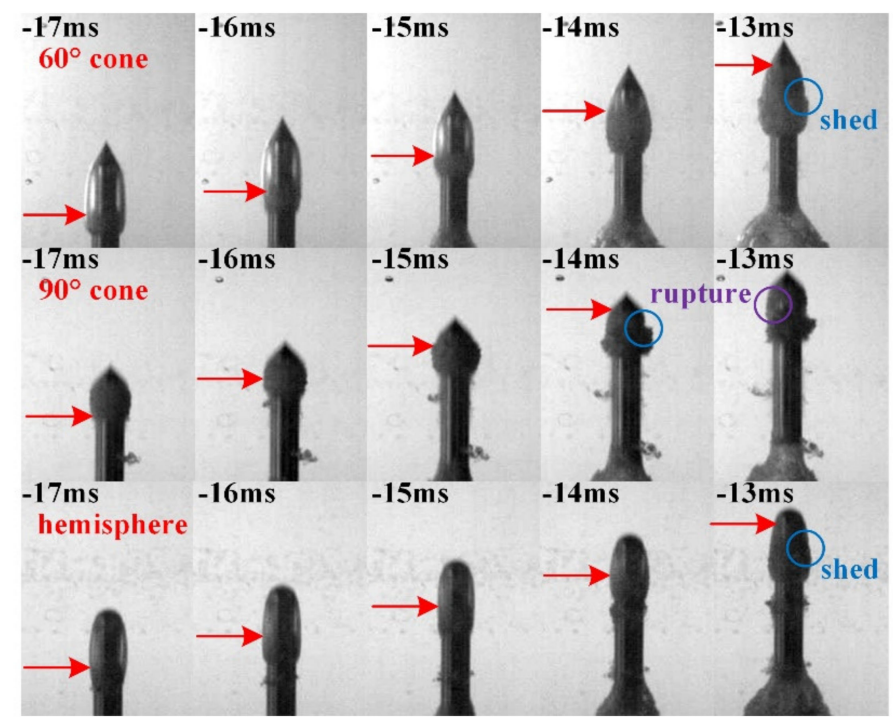

Figure 6. Development process of the re-entry jet.

From the definition and curve change of the local cavitation number, it can be seen that with the velocity and depth decreasing after launch, the value slowly increases as a quadratic curve form, which indicates that the cavitation number is mainly affected by speed. To explore the relationship between cavitation and $\sigma_{h}$, the analysis of Figure 7 combined with the cavitation evolution found that the bubbles of the $90^{\circ}$ cone head with a large $\sigma_{h}$ grow and shed randomly in a small range, which indicates that the cloud cavitation is easy to occur when $\sigma_{h}$ is small in the growth stage, while the cavitation stability is worse when $\sigma_{h}$ is larger in the shedding stage.

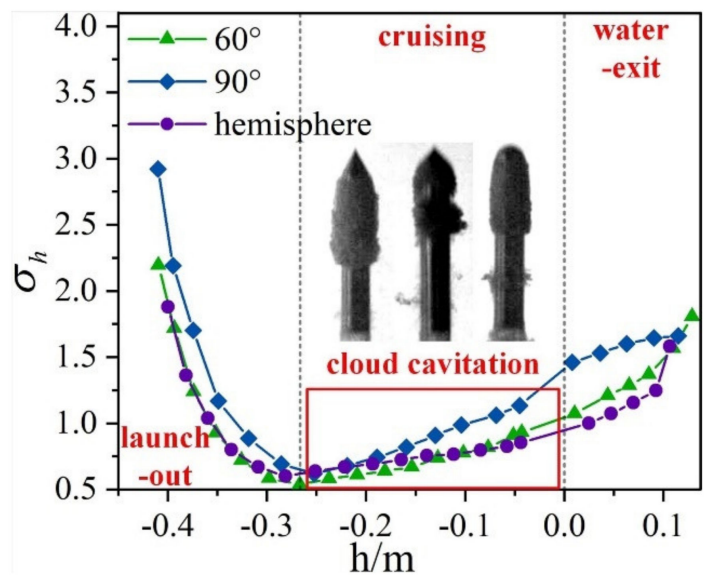

Figure 7. Variation curve of the local cavitation number with depth. 


\subsection{The Effect of Launch Speeds on Cavitation Process}

Figures 8-10 show the cavitation shape and size evolution of various head forms at two launch speeds of $16.8 \mathrm{~m} / \mathrm{s}$ and $20.0 \mathrm{~m} / \mathrm{s}$. A comparative analysis found that the effect of speeds on cavitation characteristics for different head forms has some common rules: Launch speed mainly affects the stable size of the cavity growth and the frequency of the cavity shedding. At low speed, the cavity bubbles will shed and rupture more randomly and frequently, while the bubbles will grow longer and thicker when the launch speed increases, which obviously improves the cavitation stability.

The hemispherical and $60^{\circ}$ cone head projectiles move obliquely at low speeds due to the impact of the cavity collapse and air mass from the launcher. The cavity bubbles of hemispherical heads are small and few at low speeds, while the cloud cavitation is obvious at high speed, which indicates that the cavitation is not easy to occur in the hemispherical head projectile. In addition, before the significant cloud cavitation occurs, the increase in speeds will change the shape of cavity bubbles, which will transform the cavitation cluster from a point-like distribution to a cloud-like distribution.

The $90^{\circ}$ cone and hemispherical heads with large differences in cavitation are selected for the dimensionless parameter analysis at three launch speeds. As seen from Figure 11, the local cavitation number of two head forms is small at high speed, whose cavitation development is relatively stable in Figure 8, which indicates that increasing the launch speed can reduce the cavitation number and improve the cavitation stability. Comparing the cavitation and dimensionless parameters of two heads, it is found that the cloud cavitation of hemispherical heads is obvious when the local cavitation number is low, which indicates that the hemispherical head is not prone to cavitation, whose critical cavitation number is small. When the $90^{\circ}$ cone head projectile moves slowly in a deceleration process, the size fluctuation of shedding bubbles is strong; meanwhile the curve rises sharply, which indicates that the local cavitation number increases rapidly as the speed decreases, causing cavitation unstable.

\subsection{Research on the Projectile Movement}

The projectile is launched out by the high-pressure gas in a roughly uniformly accelerated motion. Due to the multiple effects of the residual gas, fluid drag and unstable cavitation, its movement trajectory will shift gradually and its velocity will reduce slowly. When the projectile exits the water, its speed drops sharply and the motion trajectory deflects greatly by the unbalanced force of the water surface disturbance and cavitation collapse. To study the effects of head forms and launch speeds on the motion characteristics of projectiles, the speed, trajectory and deflection angle change curves are shown respectively in Figures 12-15.

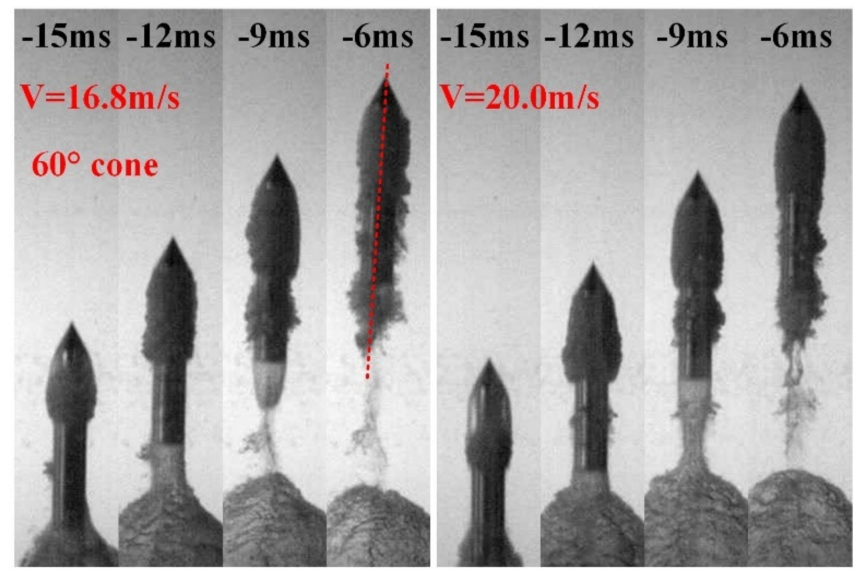

(a) $60^{\circ}$ cone head

Figure 8. Cont. 


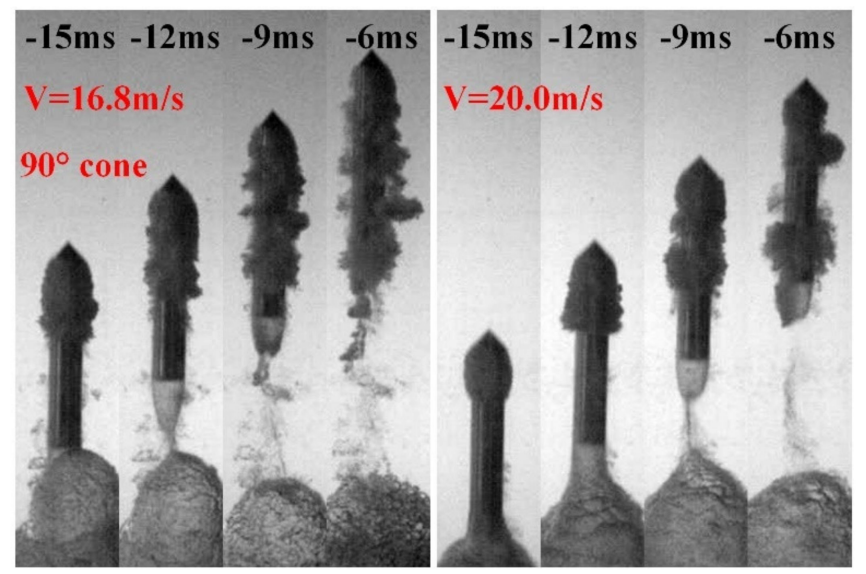

(b) $90^{\circ}$ cone head

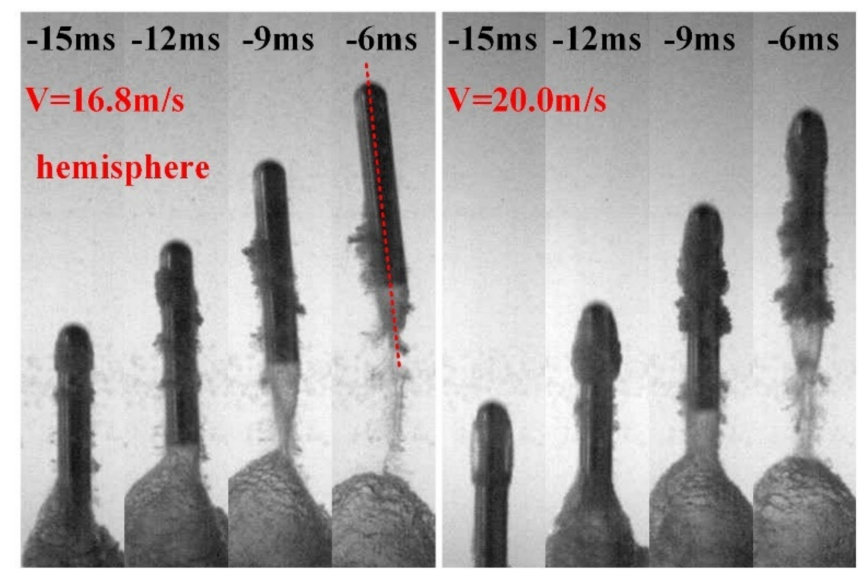

(c) hemispherical head

Figure 8. Unsteady cavitation evolution process of three head-shaped projectiles at $16.8 \mathrm{~m} / \mathrm{s}$ and $20.0 \mathrm{~m} / \mathrm{s}$. (a) $60^{\circ}$ cone head (b) $90^{\circ}$ cone head (c) hemispherical head.

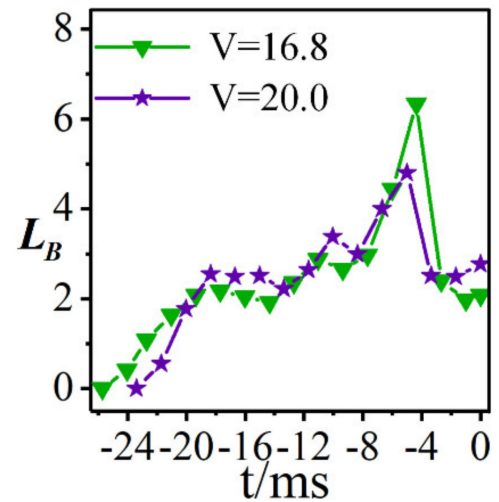

(a) bubble length

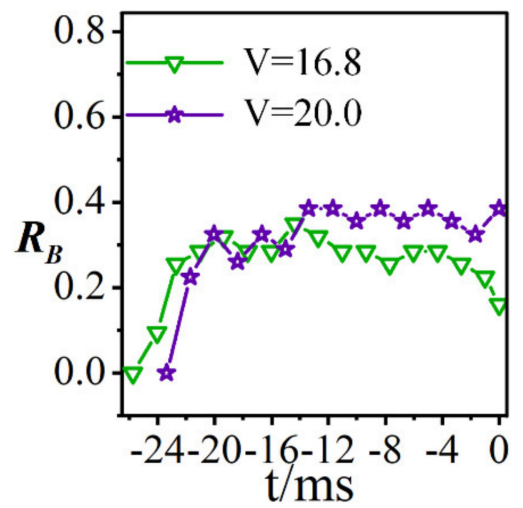

(b) maximum bubble thickness

Figure 9. Variation curve of bubble sizes of $60^{\circ}$ cone-head projectiles at $16.8 \mathrm{~m} / \mathrm{s}$ and $20.0 \mathrm{~m} / \mathrm{s}$. (a) bubble length (b) maximum bubble thickness. 


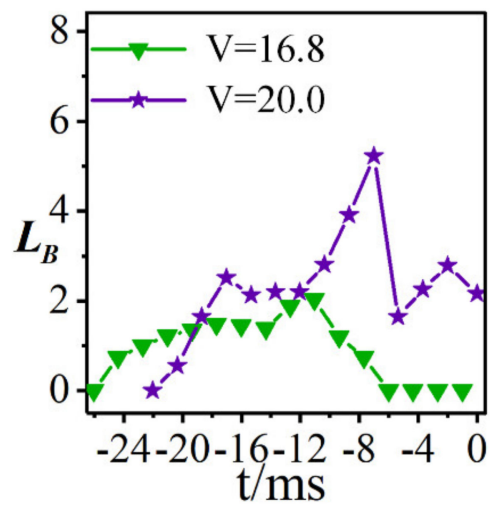

(a) bubble length

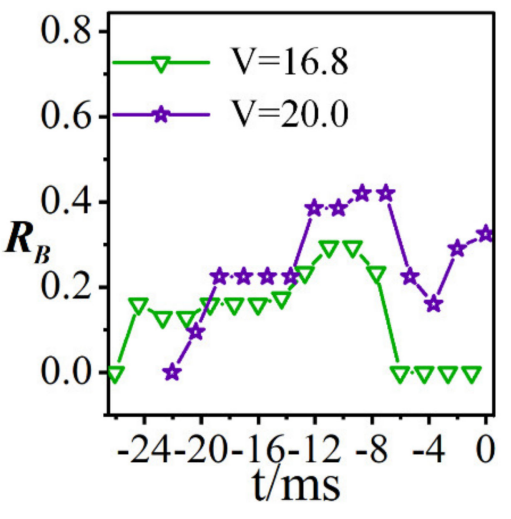

(b) maximum bubble thickness

Figure 10. Variation curve of bubble sizes of hemispherical head projectiles at $16.8 \mathrm{~m} / \mathrm{s}$ and $20.0 \mathrm{~m} / \mathrm{s}$. (a) bubble length (b) maximum bubble thickness.

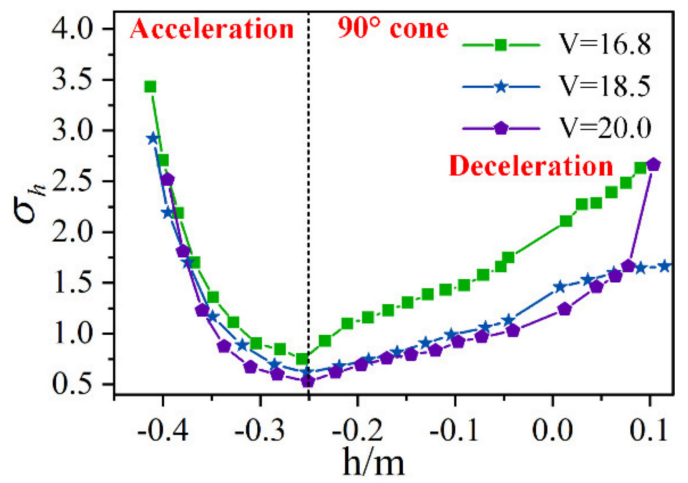

(a) $90^{\circ}$ cone head

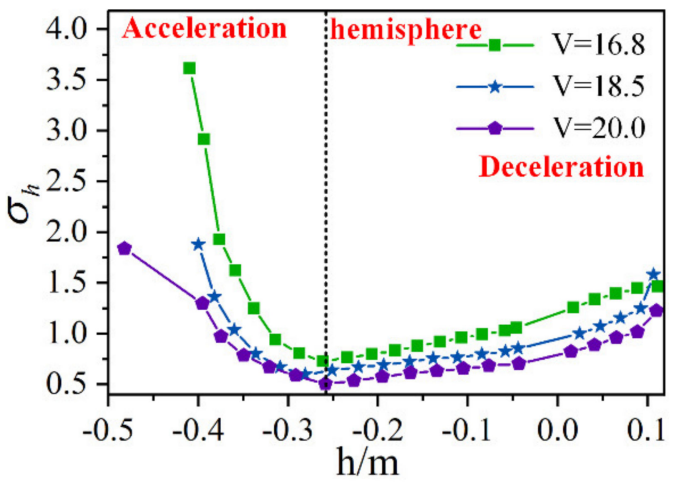

(b) hemispherical head

Figure 11. Variation curve of the local cavitation number of two head forms at different speeds. (a) $90^{\circ}$ cone head (b) hemispherical head.

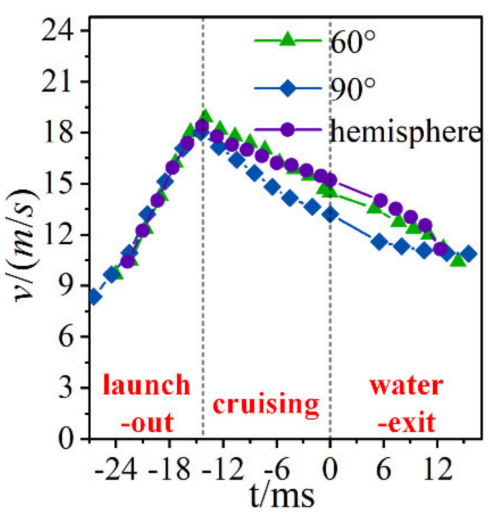

(a) movement speed

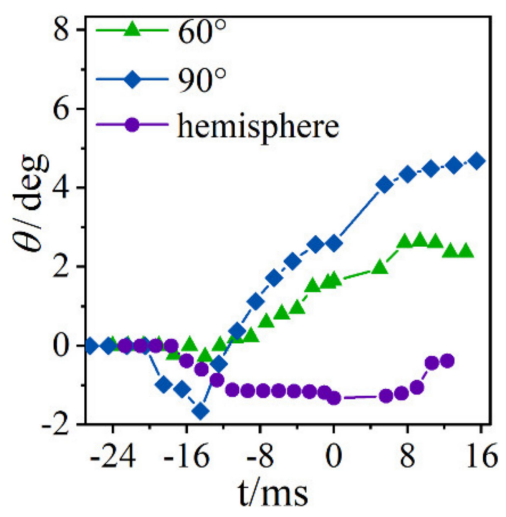

(b) movement deflection angle

Figure 12. Variation curve of motion parameters of three head-shaped projectiles. (a) movement speed (b) movement deflection angle. 


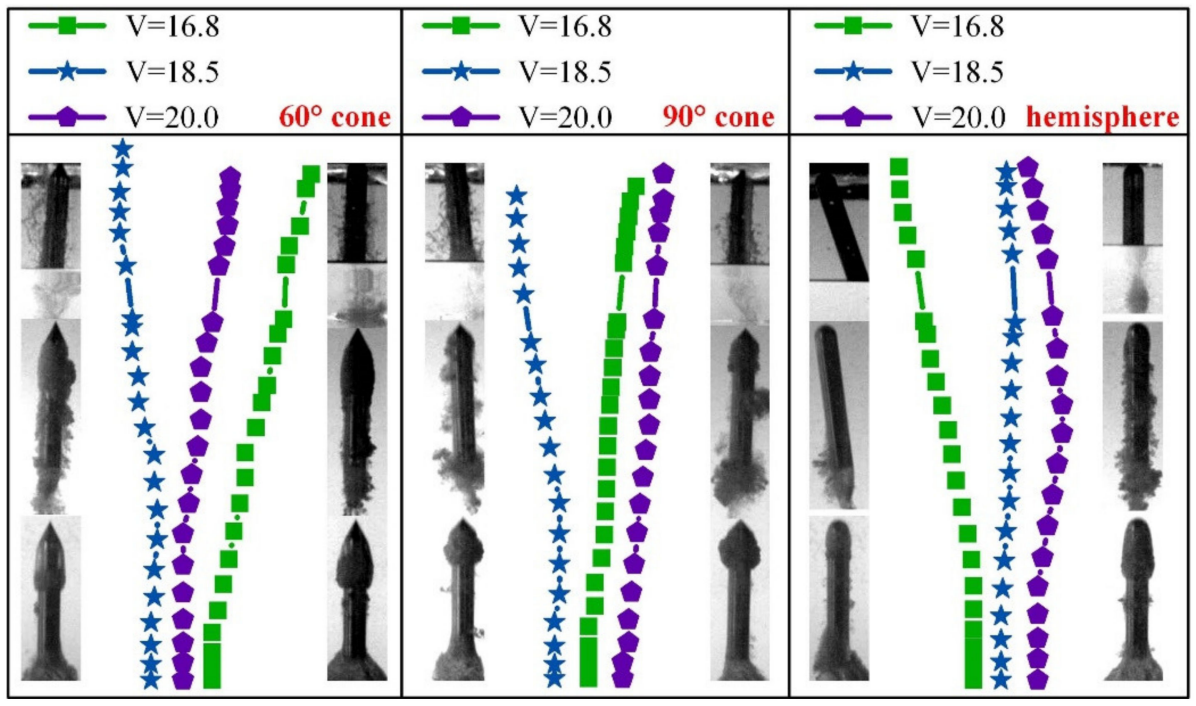

Figure 13. Trajectory curve of the projectiles under three head forms and launch speeds.

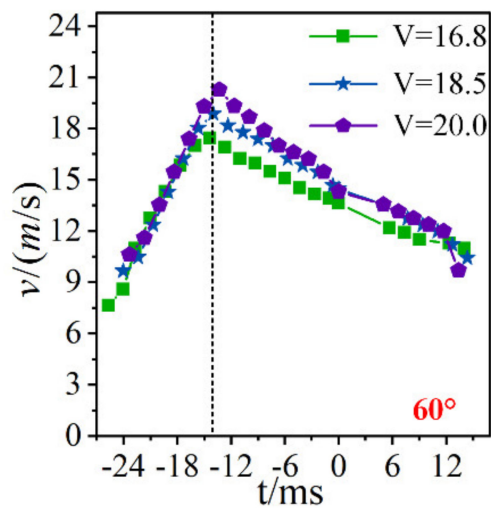

(a) $60^{\circ}$ cone head

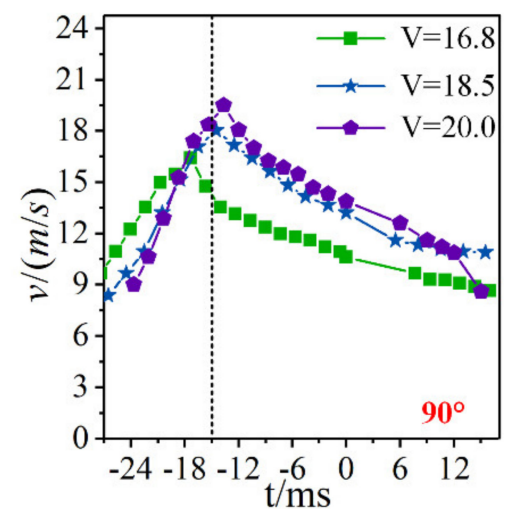

(b) $90^{\circ}$ cone head

Figure 14. Variation curve of movement speeds of two head forms at three speeds. (a) $60^{\circ}$ cone head (b) $90^{\circ}$ cone head.

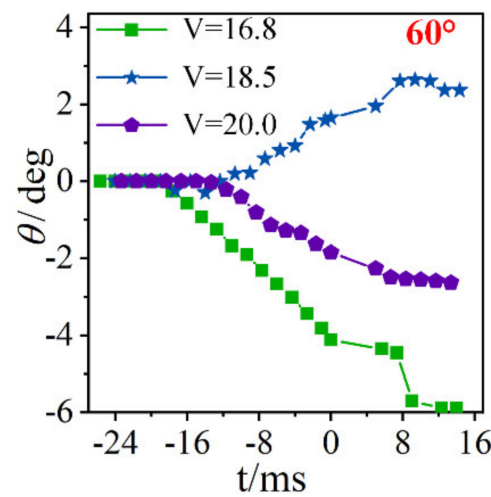

(a) $60^{\circ}$ cone head

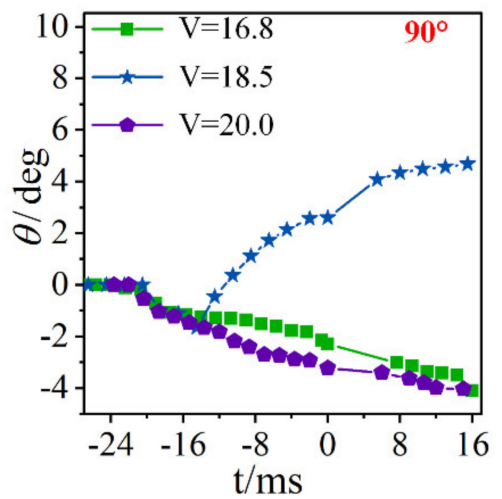

(b) $90^{\circ}$ cone head

Figure 15. Variation curve of deflection angles of two head forms at three speeds. (a) $60^{\circ}$ cone head (b) $90^{\circ}$ cone head.

Due to the difference in model quality and cavitation characteristics, the launch speeds of three head-shaped projectiles under the same pressure are not alike, as shown in Figure 12a. The launch speed of $60^{\circ}$ cone head projectiles is the largest because of its 
lightest mass; the hemispherical head projectile is heavy, but its cavitation is connected to the air mass near the launch tube, which is similar to the ventilated cavitation with a drag reduction effect; the launch speed of $90^{\circ}$ cone head projectiles is the smallest under the effects of the repeated growth, shedding and fracture of the cavitation. Therefore, the mean velocity of three variable-speed launch tests is $16.8 \mathrm{~m} / \mathrm{s}, 18.5 \mathrm{~m} / \mathrm{s}, 20.0 \mathrm{~m} / \mathrm{s}$.

Figure $12 \mathrm{~b}$ shows the variation curve of the deflection angle for three head forms when the average launch speed is about $18.5 \mathrm{~m} / \mathrm{s}$. Comparing the motion trajectories and deflection angles of three head-shaped projectiles at this speed, it is found that the hemispherical head projectile deflects less than $1^{\circ}$, so its motion characteristic is relatively stable. When the $60^{\circ}$ cone head projectile exits the water, its bubbles on two sides are not symmetrical and the collapse impact is strong, causing an unbalanced force on the projectile with a deflection of about $2.5^{\circ}$. The deflection of $90^{\circ}$ cone head projectiles is seriously affected by the attached cavitation shedding and collapse, so its motion stability is poor.

Figures 14 and 15 show the variation curve of motion parameters for conical head projectiles. It can be found that the variation range of movement speeds and deflection angles of the $60^{\circ}$ cone head is smaller than that of the $90^{\circ}$ cone head, which indicates that the motion of $60^{\circ}$ cone head projectiles is relatively stable. As shown in Figure 14, because drag is positively related to speed, the projectile at high speed is interfered significantly by the fluid, so that its velocity reduces rapidly. As seen from Figures 13 and 15, three headshaped projectiles deflect severely at low and medium speeds, while the deflection angle reduces as the speed increases, indicating that the increasing launch speed can improve motion stability.

\section{Conclusions}

Based on a self-designed underwater launch platform, this paper carried out vertical water-exit tests of scaled models with different head forms and launch speeds. Through the further analysis of the unsteady cavitation and projectile movement, the conclusions were obtained as follows:

(1) Cavitation evolution experiences three stages: stable growth, shedding with rupture, and collapse. A phase change occurs at the low-pressure area of the projectile's shoulder, forming cavitation. Affected by the re-entry jet, the cavity falls off from its tail to head. The cavity collapses quickly from its top to bottom out of the water with a strong impact jet, which causes the projectile to deflect.

(2) The research on the relationship between the re-entry jet and cavitation number with cavitation stability indicates that: the periodic development of the re-entry jet and cavitation affects the shedding frequency together; the cavitation can be predicted by the cavitation number-when its value is small, the phase change occurs easily with large cavity growth size and low shedding frequency.

(3) Comparing the cavitation and movement of different head forms and launch speeds, it is found that the hemispherical head is anti-cavitation. The cavitation development of the $90^{\circ}$ cone head shows a small area of the high-frequency growth and shedding. The cavitation evolution of the $60^{\circ}$ cone head is easily affected by the gas near the tube. The launch speed affects the growth size and shedding frequency of bubbles mainly, so it can improve the stability of the cavitation evolution and projectile's movement by increasing the launch speed.

Author Contributions: Conceptualization and methodology, all authors; validation, S.C. and S.G.; resources, S.C., S.G. and Y.S.; investigation, S.C. and S.G.; data curation, formal analysis, visualization and writing - original draft, S.C.; writing-review and editing, Y.S. and S.C.; supervision and project administration, Y.S. and G.P.; funding acquisition, G.P. All authors have read and agreed to the published version of the manuscript.

Funding: The research was supported by the National Natural Science Foundation of China (Grant No. 52171324) and the Fundamental Research Funds for the Central Universities (Grant No. 3102019JC006). 
Data Availability Statement: All data and models generated or used during the research period appear in the submitted manuscript.

Conflicts of Interest: The authors have no conflict of interest and unanimously agree to submit the manuscript to the journal.

\section{References}

1. Knapp, R.T. Recent investigations of the mechanics of cavitation and cavitation damage. J. Appl. Mech. 1955, 77, 1045-1054.

2. Geurst, J.A. Linearized theory for partially cavitated hydrofoils. Int. Shipbuild. Prog. 1959, 6, 369-384. [CrossRef]

3. Logvinovich, G.V. Hydrodynamics of Flows with Free Boundaries; Naukova Dumka: Kiev, Ukraine, $1969 ;$ p. 16.

4. Brennen, C.E. Cavitation and Bubble Dynamics; Oxford University: New York, NY, USA, 1995.

5. Plesset, M.S.; Chapman, R.B. Collapse of an initially spherical vapour cavity in the neighbourhood of a solid boundary. J. Fluid Mech. 1970, 47, 283-290. [CrossRef]

6. Liu, D.C.; Hong, F.W.; Fang, L. The numerical and experimental research on unsteady cloud cavitating flow of $3 d$ elliptical hydrofoil. J. Hydrodyn. B 2010, 22, 759-763. [CrossRef]

7. Leroux, J.B.; Astolfi, J.A.; Billard, J.Y. An experimental study of unsteady partial cavitation. J. Fluids Eng. 2004, 126, 94-101. [CrossRef]

8. Kubota, A.; Kato, H.; Yamaguchi, H.; Maeda, M. Unsteady structure measurement of cloud cavitation on a foil section using conditional sampling technique. J. Fluids Eng. 1989, 111, 204-210. [CrossRef]

9. Le, Q.; Franc, J.P.; Michel, J.M. Partial cavities: Global behavior and mean pressure distribution. J. Fluids Eng. 1993, 115, $243-248$. [CrossRef]

10. Kjeldsen, M.; Arndt, R.; Effertz, M. Spectral characteristics of sheet/cloud cavitation. J. Fluids Eng. 2000, 22, 481-487. [CrossRef]

11. Wang, G.; Ostoja-Starzewski, M. Large eddy simulation of a sheet/cloud cavitation on a NACA0015 hydrofoil. Appl. Math. Model. 2007, 31, 417-447. [CrossRef]

12. Huang, B.; Young, Y.L.; Wang, G.; Shyy, W. Combined experimental and computational investigation of unsteady structure of sheet/cloud cavitation. J. Fluids Eng. 2013, 135, 071301. [CrossRef]

13. Gu, W.; He, Y.; Hu, T. Transcritical patterns of cavitating flow and trends of acoustic level. J. Fluids Eng. 2001, 123, 850-856. [CrossRef]

14. Yu, X.; Huang, C.; Du, T.; Liao, L.; Wu, X.; Zheng, Z.; Wang, Y.W. Study of characteristics of cloud cavity around axisymmetric projectile by large eddy simulation. J. Fluids Eng. 2014, 136, 051303. [CrossRef]

15. Wei, H.; Song, F.; Qin, W.; Huang, B.; Wang, G. Experimental and numerical research on cavitating flows around axisymmetric bodies. J. Mech. Sci. Technol. 2014, 28, 4527-4537.

16. Hu, C.L.; Wang, G.Y.; Wang, X.D.; Huang, B. Experimental investigation of inception cavitating flows around axisymmetric bodies with different headforms. J. Mech. Sci. Technol. 2016, 30, 3193-3201. [CrossRef]

17. Chen, Y.; Lu, C.; Chen, X.; Cao, J. Numerical investigation on the cavitation collapse regime around the submerged vehicles navigating with deceleration. Eur. J. Mech. B Fluids 2015, 49, 153-170. [CrossRef]

18. Wan, C.R.; Liu, H. Shedding frequency of sheet cavitation around axisymmetric body at small angles of attack. J. Hydrodyn. B 2017, 29, 520-523. [CrossRef]

19. Zhao, C.G.; Wang, C.; Wei, Y.J.; Zhang, X.S. An experimental study on characteristics of cavitation and ballistic of axisymmetric slender body underwater movement. J. Phys. Conf. Ser. 2015, 656, 012175. [CrossRef]

20. Sun, T.; Zhang, X.; Zhang, J.; Wang, C. Experimental Study on the Unsteady Natural Cloud Cavities: Influence of Cavitation Number on Cavity Evolution and Pressure Pulsations. J. Mar. Sci. Eng. 2021, 9, 487. [CrossRef]

21. Chu, X.S.; Kai, Y.; Zhi, W.; Ke, Z.; Feng, G.; Chen, W.Q. Numerical simulation of water-exit of a cylinder with cavities. J. Hydrodyn. $B$ 2010, 22, 877-881. [CrossRef]

22. Cao, J.-Y.; Lu, C.-J.; Chen, Y.; Chen, X.; Li, J. Research on the base cavity of a sub-launched projectile. J. Hydrodyn. B 2012, 24, 244-249. [CrossRef]

23. You, T.Q.; Cao, W.; Wei, Y.J.; Zhang, J.Z.; Wang, C. Simulation of the cavity collapse during the cavity crossing water free surface. JSME. Int. J. A-Solid Mech. 2010, 4, 1360-1368. [CrossRef]

24. Zhang, J.Z.; You, T.Q.; He, Q.K.; Wei, Y.J.; Wang, C. Numerical analysis of cavitation flow during vertical water exit of underwater vehicles. Adv. Mater. Res. 2011, 201-203, 2780-2784. [CrossRef]

25. Liu, H.J.; Peng, X.Z.; Wang, C.; Wang, B.L. Investigation on influence of launch depth to the hydrodynamic characteristics of the cylinder out of the tube. Adv. Mater. Res. 2011, 328-330, 2261-2264. [CrossRef]

26. Cao, W.; You, T.Q.; Wei, X.B.; Wang, C.; Zhao, X.H. Numerical study on air-involved cavity during water exit of underwater vehicle. Procedia Earth Planet. Sci. 2012, 5, 203-208.

27. Wang, Y.; Liao, L.; Du, T.; Huang, C.; Liang, N. A study on the collapse of cavitation bubbles surrounding the underwater-launched projectile and its fluid-structure coupling effects. Ocean. Eng. 2014, 84, 228-236. [CrossRef]

28. Wang, Y.; Huang, C.; Fang, X.; Wu, X.; Du, T. On the internal collapse phenomenon at the closure of cavitation bubbles in a deceleration process of underwater vertical launching. Appl. Ocean Res. 2016, 56, 157-165.

29. Chen, Y.; Gong, Z.X.; Li, J.; Chen, X.; Lu, C.J. Numerical Investigation on the Regime of Cavitation Shedding and Collapse During the Water-Exit of Submerged Projectile. J. Fluids Eng. 2020, 142, 011403. [CrossRef] 
30. Quan, X.; Li, Y.; Wei, H.; Lv, H.B.; Xin, W.Q.; Lu, C.J. Cavitation collapse characteristic research in the out-of-water progress of underwater vehicles. J. Ship Mech. 2008, 12, 545-549. (In Chinese)

31. Fu, G.Q.; Zhao, J.L.; Sun, L.P.; Lu, Y. Experimental Investigation of the Characteristics of an Artificial Cavity during the Water-Exit of a Slender Body. J. Mar. Sci. Appl. 2018, 17, 578-584. [CrossRef]

32. Song, X.; Wu, Q.G.; Ni, B.Y.; Chen, H.L. Deformation and bubble entrapment of free surface before axisymmetric bodies detaching from water fully. J. Mech. 2019, 35, 1-12.

33. Wang, Y.; Huang, C.; Wu, X.; Du, T.; Fang, X.; Liang, N.; Yu, X. Investigation of cavities shedding condition on underwater vehicles in the vertical launch process. Eng. Mech. 2015, 32, 33-39. (In Chinese) [CrossRef] 